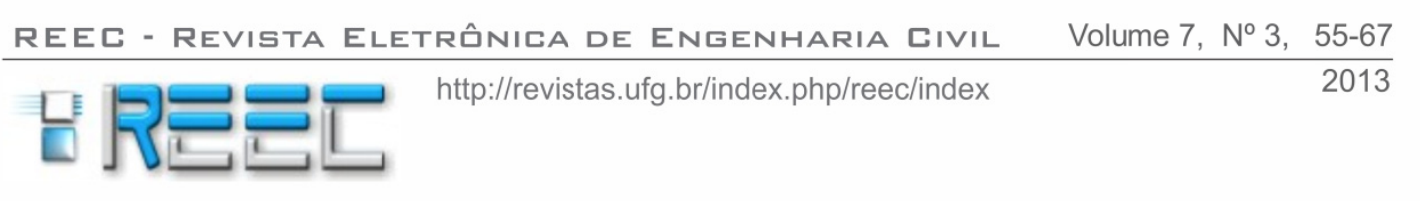

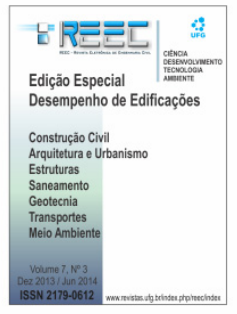

\title{
SISTEMAS PREDIAIS DE INFILTRAÇÃO DE ÁGUA DE CHUVA: APLICAÇÕES, LIMITAÇÕES E PERSPECTIVAS
}

\section{Storm water infiltration for building systems: applications, limitations and perspectives}

\begin{abstract}
Ricardo Prado Abreu reis ${ }^{1}$, Marina Sangoi de Oliveira llha $^{2}$ e Paula de Castro Teixeira ${ }^{3}$
Recebido em 07 de novembro de 2013; recebido para revisão em 05 de dezembro de 2013; aceito em 18 de dezembro de 2013; disponivel on-line em 30 de dezembro de 2013.

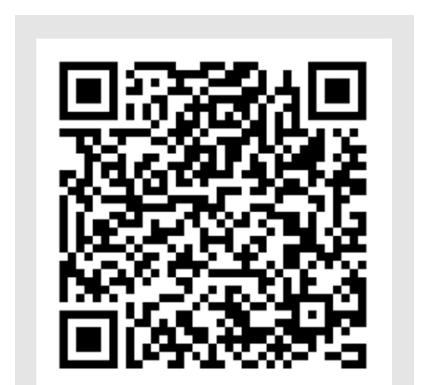

PALAVRAS CHAVES:

Drenagem na fonte;

Infiltração de água de chuva;

Desenvolvimento de baixo impacto.

KEYWORDS:

On-site drainage;

Storm water infiltration;

Low impact

development.
\end{abstract}

* Contato com o autor:

${ }^{1}$ e-mail : ricardo_reis@ufg.br

Professor do curso de Engenharia Civil da Universidade Federal de Goiás, Doutorando em Engenharia Civil pela Faculdade de Engenharia Civil, Arquitetura e Urbanismo da UNICAMP.

2e-mail : milha@fec.unicamp.br (M.S.O. Ilha)

Professora Livre Docente do curso de Engenharia Civil e Arquitetura da Faculdade de Engenharia Civil, Arquitetura e Urbanismo da Faculdade de Engenharia Civil, Arquitetura e Urbanismo - UNICAMP.

${ }^{3}$ e-mail : paulacteixeira@gmail.com ( P. C. Teixeira )

Arquiteta, Mestre em Eng. Civil pela Faculdade de Engenharia Civil, Arquitetura e Urbanismo da UNICAMP.

(C) 2013 REEC - Todos os direitos reservados.

\section{INTRODUÇÃO}

Os impactos ocasionados pelo processo de urbanização têm se mostrado mais intensos nas últimas décadas. No ano de 1800 apenas $1 \%$ da população mundial vivia em meios urbanos (Bertoni e Tucci, 2003), já no início de 2010, foi estimado pelo World Resources Institute (2007) 
uma concentração da população mundial nos centros urbanos de $50,8 \%$ da população total. Estima-se ainda que em 2030 a população concentrada em centros urbanos atinja a marca de $60 \%$ do total (World Economic Forum, 2009). No Brasil, a região hidrográfica do Paraná, por exemplo, onde se localiza a cidade de São Paulo, a população urbana já atingiu mais de 90\% (ANA, 2007 e IBGE, 2006).

A grande concentração populacional em áreas urbanas implica em mudanças significativas nas características do ambiente ocupado, visto que o homem busca alterar o meio em que vive da forma que melhor se ajuste às suas necessidades. 0 processo de urbanização acelerado na maioria dos casos ocorre de forma não planejada e, quase sempre vem acompanhado de uma série de impactos ambientais e problemas de infraestrutura urbana: retirada da vegetação nativa, alteração do relevo natural, introdução de grandes áreas com superfícies impermeáveis, uso indiscriminado do solo, eliminação de pontos de recarga de mananciais subterrâneos, mudanças de direção ou canalização de cursos d'água, disposição inadequada de resíduos, entre outros.

O desequilíbrio do balanço hídrico pode ser citado como um dos grandes impactos gerados nas regiões ocupadas. A diminuição do volume de água infiltrada no solo em uma área urbanizada é significante se comparada às condições originais das regiões com grande urbanização. A alteração no hidrograma é observada por acréscimos nos picos de vazões, com o aumento do volume em um curto espaço de tempo. Como resultado, tem-se as enxurradas e cheias urbanas (CARVALHO, 2008).

A solução convencional para a drenagem urbana consiste na execução de galerias pluviais para a coleta e transporte do excesso de escoamento superficial para pontos à jusante das áreas urbanas. Entretanto, esta forma de concepção de sistemas de drenagem nem sempre suporta a magnitude das vazões de escoamento nos pontos de descarga. O problema se agrava devido aos seguintes fatores: impermeabilização de grandes áreas urbanas ocasionada pela ocupação desordenada, pontos de redes de drenagem subdimensionados e ao mau funcionamento destas galerias em função de entupimentos provocados pelo lixo não coletado ou disposto incorretamente.

Com a tendência de adoção de conceitos de desenvolvimento de baixo impacto ambiental, soluções complementares de drenagem urbana vêm sendo estudadas ao longo das últimas décadas. Este conceito, relativamente novo, se traduz na tentativa de manutenção das condições de equilíbrio do balanço hídrico existentes no período de pré-desenvolvimento. As soluções devem ser implementadas diretamente na fonte de geração do problema. Para tanto, deve-se utilizar novos conceitos como os dispositivos de acréscimo de infiltração, de armazenamento e retardo do escoamento, além de integração de medidas não estruturais, que visem à prevenção das causas dos problemas e não de seus efeitos (REIS et al. 2006)

Diante da verificação do mau desempenho dos sistemas convencionais de drenagem urbana, evidencia-se a necessidade de implantação de ações de controle de drenagem, mais sustentáveis, que restabeleçam o equilíbrio hidrológico e minimizem os impactos da urbanização. Algumas destas ações devem ser introduzidas nos sistemas hidráulicos prediais como, por exemplo, a concepção de projetos de sistemas de drenagem na fonte, ferramentas que promovem a retenção, detenção e infiltração da água de chuva no próprio local onde o escoamento é gerado.

É importante ressaltar que apesar da existência de inúmeros conceitos e técnicas de drenagem de águas pluviais que buscam soluções mais eficientes e de menor impacto, muitas dessas técnicas não são hoje empregadas ou, em alguns casos, são utilizadas inadequadamente, por causa da inexistência de uma base de dados técnicos que possibilitem uma correlação mais precisa entre parâmetros locais e critérios de concepção.

$O$ estudo de sistemas de drenagem na fonte que possibilitam o desenvolvimento do ambiente construído proporcionando um menor impacto ambiental se justifica em função:

- da necessidade de se aprofundar a discussão e a divulgação de soluções alternativas sobre o controle e o desenvolvimento de sistemas de drenagem urbana de forma sistêmica, devido à falta de eficiência dos sistemas 
implantados atualmente nos centros urbanos quanto ao impedimento de formação de cheias;

- da necessidade do desenvolvimento de técnicas mais aprimoradas de concepção e operação dos sistemas de drenagem na fonte proporcionando, assim, uma aplicação mais eficiente desses sistemas em áreas edificadas;

- do conhecimento restrito a respeito das formas de aplicação, das limitações e das perspectivas que envolvem o uso de soluções embasadas nos conceitos de desenvolvimento de baixo impacto.

Assim, o objetivo deste trabalho é reunir os resultados obtidos em diferentes pesquisas relevantes a respeito de sistemas de drenagem na fonte com enfoque em soluções de infiltração, forma que se possa realizar uma avaliação crítica a respeito dos avanços obtidos e do estado atual de maturidade desta tecnologia, além da necessidade de estudos futuros e dos desafios a serem enfrentados para a promoção mais ampla desta tecnologia.

\section{MATERIAL E MÉTODOS}

Diversas pesquisas sobre práticas de desenvolvimento de baixo impacto (Low Impact Development - LID) aplicadas a lotes urbanos individuais, também conhecidas como sistemas de drenagem na fonte, vêm sendo desenvolvidas nas últimas décadas. Como produto destas pesquisas, várias publicações a respeito do estudo de concepção, desempenho e desenvolvimento dos conceitos de LID foram publicados, principalmente após a divulgação de uma revisão literária sobre o tema lançada pela Environmental Protection Agency - EPA em 2000 (DIETZ, 2007).

Apesar da evolução do conhecimento a respeito das técnicas de drenagem na fonte, ainda são frequentes os questionamentos no meio técnico e científico sobre a eficácia de aplicação destas ferramentas para o controle de escoamento superficial em áreas urbanas. Assim, por meio da investigação bibliográfica de pesquisas relevantes já publicadas sobre a aplicação de práticas de LID, foi realizada uma síntese do status atual de desenvolvimento das soluções de drenagem na fonte. Para um maior foco na busca de informações e dados bibliográficos, foram formuladas as seguintes questões, as quais estão relacionadas com o objetivo declarado dessa pesquisa:

- Qual o propósito de implantação de práticas de desenvolvimento de baixo impacto (LID)?

- Qual o desempenho destas soluções no controle de enxurradas?

- Quais os parâmetros de projeto e critérios de concepção de práticas LID?

- Qual o custo da aplicação deste novo conceito nos sistemas de drenagem urbana?

- Quais os benefícios e limitações técnicas da adoção de soluções de drenagem na fonte embasadas em práticas LID?

Juntamente com a investigação do estágio atual de desenvolvimento das tecnologias de drenagem na fonte, a resposta a estas perguntas também fornecerá subsídios para a identificação dos pontos que ainda necessitem de pesquisas mais aprofundadas para uma aplicação mais criteriosa em larga escala das práticas de desenvolvimento de baixo impacto ambiental.

Para responder a estas questões, o item seguinte apresenta uma revisão bibliográfica a respeito das principais tipologias de sistemas de drenagem na fonte estudadas na atualidade.

\section{SISTEMAS DE DRENAGEM NA FONTE}

A geração de grandes volumes de escoamento superficial é uma das consequências do crescimento desordenado e ampliação de áreas impermeabilizadas, proporcionadas pelo processo de desenvolvimento das cidades.

O excesso de escoamento superficial incide diretamente na alteração do hidrograma de escoamento da área urbanizada (Figura 1).

Comparando-se o perfil de escoamento pré e pós-urbanização verifica-se uma acentuada elevação do pico de vazão devido à redução da capacidade de retenção e infiltração do solo. Este acréscimo de volume e de velocidade de escoamento superficial em muitos casos caracteriza o processo de formação de enxurradas e cheias urbanas. 


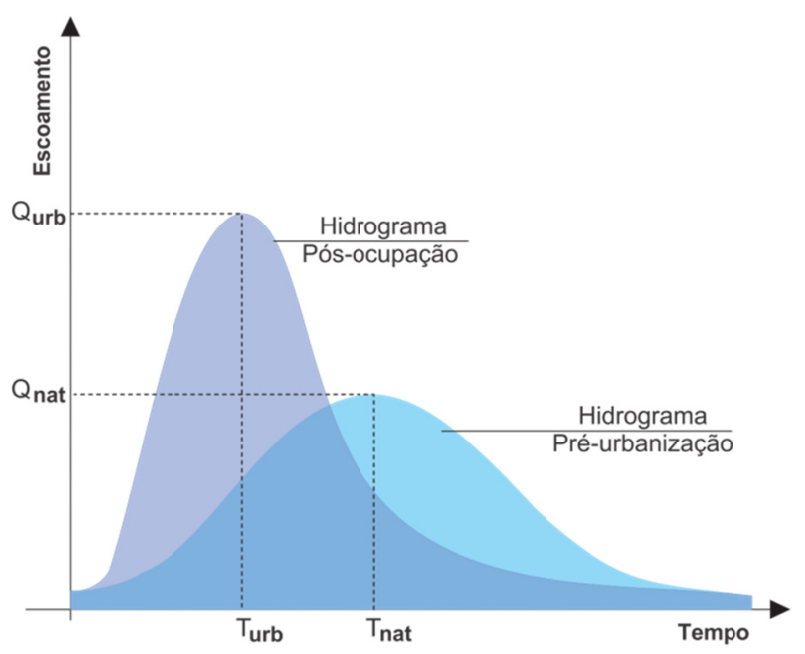

FIGURA 1: Hidrogramas representativos de áreas pré e pós urbanização.

Dentre as técnicas compensatórias de drenagem urbana para a solução desse problema, podem ser citados os sistemas de drenagem na fonte, os quais se constituem em ferramentas que possibilitam o manejo mais sustentável das águas pluviais e, assim, integram soluções de drenagem que geram um menor impacto durante o uso e ocupação do solo em áreas urbanas.

Atualmente, estas técnicas constituem o que o meio técnico internacional vem chamando de BMPs - Best Management Practices. Esta denominação integra o conceito de LID - Low Impact Development e de WSUD - Water Sensitive Urban Design que são termos mais amplos.

O termo LID consiste em se estabelecer estratégias de desenvolvimento urbano e técnicas de gerenciamento de águas pluviais aplicadas a parcelas pequenas ou individuais de solo urbano, que visam conservar as características naturais do terreno integradas com as ações da engenharia. ${ }^{9} \mathrm{O}$ termo WSUD engloba um sistema de gestão de água no meio urbano que integra o conceito de LID, metodologias de conservação e reciclagem de água, gestão da qualidade da água urbana e ecologia. ${ }^{10}$

Assim, de acordo com a metodologia apresentada, pode-se responder a primeira questão levantada: qual o propósito de implantação de práticas de desenvolvimento de baixo impacto (LID)? Pode-se dizer que o propósito da adoção de sistemas de drenagem na fonte em áreas urbanas edificadas consiste em não permitir a ampliação da vazão de escoamento superficial do hidrograma de um lote ou área em ocupação, por meio da manutenção do balanço hídrico existente antes o processo de urbanização.

Os sistemas de controle na fonte são constituídos por unidades auxiliares de drenagem, baseadas em técnicas de infiltração, filtração, retenção e detenção, que preservam ou minimizam os impactos sobre as condições do balanço hidrológico das bacias pré-urbanizadas possibilitando, assim, menor solicitação das medidas de controle estruturais de macrodrenagem urbana. Quando concebidos corretamente, esses sistemas são capazes de reduzir o volume e a velocidade do escoamento superficial e, também, manter os pontos de recarga dos lençóis freáticos e artesianos, além de promover o melhoramento da qualidade das águas devido a diminuição da poluição difusa escoada nas superfícies urbanas ou tratadas em soluções que contemplam o processo de filtração (METROPOLITAN COUNCIL ENVIRONMENTAL SERVICES, 2001).

Nos sistemas de infiltração, a água de chuva é encaminhada para dentro de uma unidade de drenagem, dimensionada para armazenar um determinado volume de projeto, enquanto a mesma infiltra lentamente no solo. Os sistemas de filtração promovem a melhoria da qualidade da água de escoamento superficial, podendo promover a remoção de metais pesados, óleos e graxas, nutrientes e sedimentos. Os sistemas de retenção impedem que todo o volume de água captado do escoamento superficial retorne ao sistema de drenagem convencional, destinando a água captada para aproveitamento em ações que não necessitem água potável ou, então, promovendo sua infiltração posteriormente. Por último o sistema de detenção, promove a redução da velocidade de escoamento por meio do armazenamento temporắrio da água de chuva captada.

Dentre as inúmeras variações das técnicas de concepção dos sistemas de drenagem na fonte, as soluções que envolvem infiltração da água de chuva no solo, têm sido frequentemente estudadas e empregadas. A tendência de adoção de sistemas 
de infiltração de água de chuva para o controle da vazão de escoamento superficial em lotes urbanos é baseada no sentimento de que esta é a solução de maior sustentabilidade dentre as técnicas de drenagem na fonte.

Assim, a seguir são descritos alguns dos sistemas de drenagem na fonte baseados em técnicas de infiltração que podem ser utilizados em edificações urbanas para promover o controle do escoamento superficial (Figura 2): (a) pavimentos permeáveis, (b) poços de infiltração, (c) jardins drenantes e (d) trincheiras de infiltração. Estes itens respondem a pergunta número dois, que questionam a respeito do desempenho dos sistemas de drenagem na fonte.

Pavimentos permeáveis são superfícies que direcionam o fluxo da água que escoa sobre as mesmas para uma camada sob o pavimento. Essa camada funciona como um reservatório que proporciona a infiltração gradual da água de chuva para o solo (NASCIMENTO e BAPTISTA, 2009 e URBONAS e STAHRE, 1993). Podem ser construídos com blocos de concreto vazados,

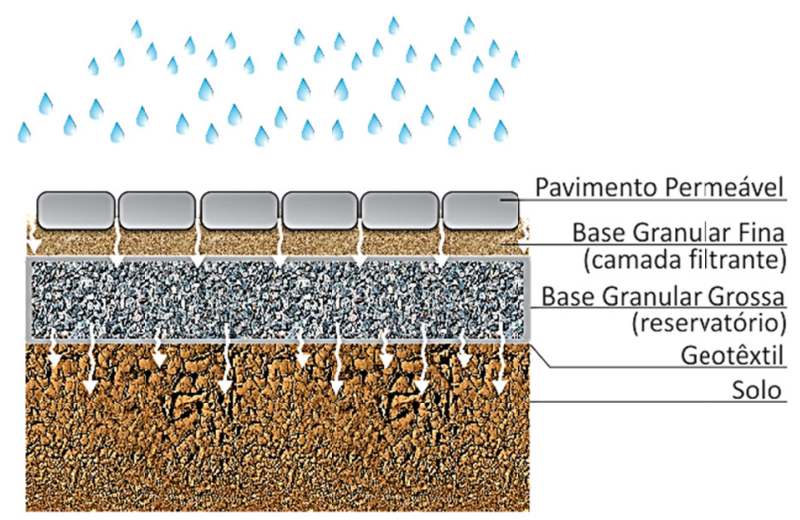

(a) Pavimento Permeável

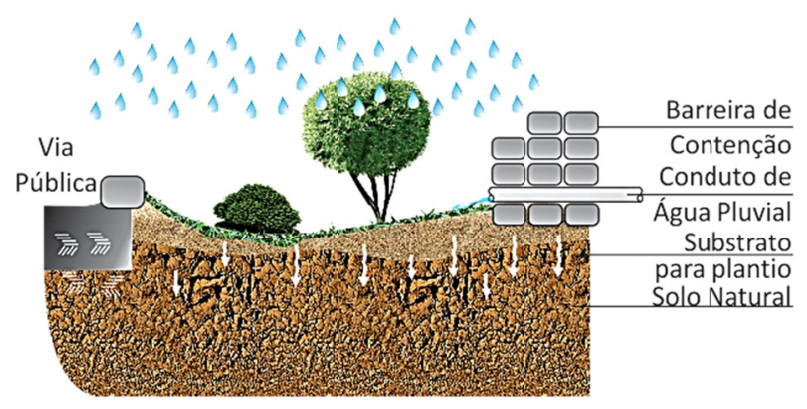

(c) Jardim de Infiltração blocos intertravados, superfícies gramadas, concregrama, asfalto e concreto poroso ou qualquer outra superfície que permita que a água percole através da mesma. Para que a superfície seja efetivamente permeável recomenda-se que os pavimentos sejam assentados sobre duas camadas de agregados de diferentes granulometrias, de tal forma que permitam o armazenamento temporário e a percolação da água captada.

A camada mais profunda, composta de agregados maiores, deve ser revestida por uma manta geotêxtil a fim de evitar a entrada de sólidos finos e a obstrução dos vazios que servirão para a retenção da água de chuva. Os pavimentos permeáveis podem ser utilizados como sistemas de drenagem superficial, com boa eficiência em áreas de estacionamentos ou trafego leve de veículos em substituição aos pavimentos impermeáveis, tais como o asfalto. Pavimentos tipo blocos vazados, intertravados ou blocoss vazados, assentados diretamente sobre o solo natural compactado, também são considerados, por muitos profissionais da construção, como pavimentos permeáveis.

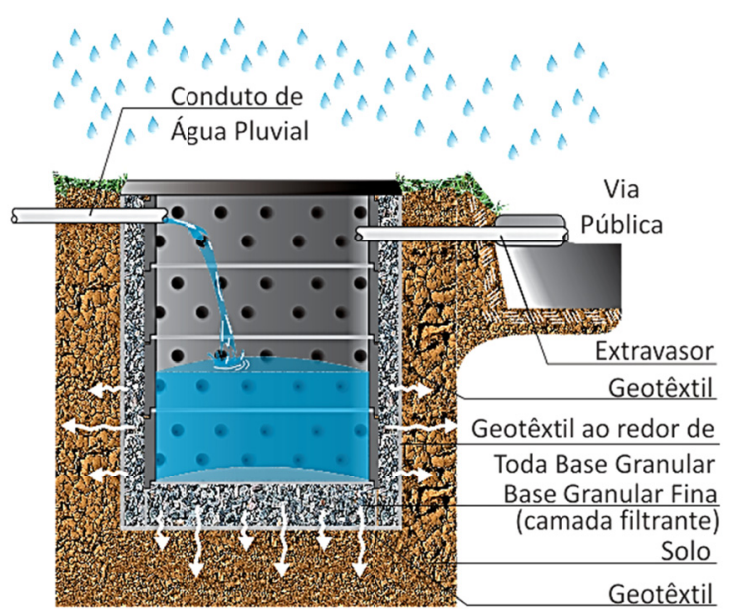

(b) Poço de Infiltração

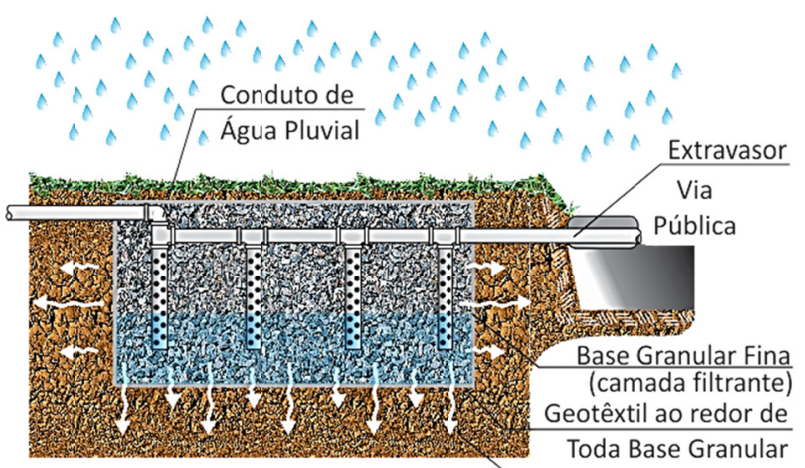

(d) Trincheira de Infiltração Solo

FIGURA 2: Sistemas de drenagem na fonte baseadas em técnicas de infiltração de água de chuva. 
Entretanto, não realizam a função de drenagem superficial com a mesma eficiência dos pavimentos permeáveis (SILVA et al., 2009).

Diferentes pesquisas comprovam o bom desempenho dos pavimentos permeáveis como sistemas de drenagem na fonte. A avaliação de chuvas reais ou simuladas de diferentes intensidades em solos compactados, blocos vazados, concreto poroso, concerto convencional, asfalto poroso, bloquetes e paralelepípedos em diferentes áreas e configurações, resultaram em coeficientes de escoamento superficial baixos, variando de 2.3 a $5.0 \%$ do volume precipitado (ARAÚJO e TUCCI, 2000 e ACIOLI et al., 2004). Foi avaliada, também, a eficiência de pavimentos permeáveis colocados diretamente sobre o terreno, sem a interposição do reservatório de brita, uma técnica de execução inadequada, porém bastante comum. Nesses casos, os coeficientes de escoamento superficial oscilaram entre $13 \%$ e $39 \%$ para os pavimentos recém instalados e, entre $53 \%$ e $69 \%$ quando em uso. Com a compactação devido à passagem de veículos, o coeficiente de escoamento superficial atingiu $79 \%$ do volume precipitado, demonstrando a ineficiência dessa técnica de execução (SILVA et al., 2009). Uma importante aplicação de pavimentos permeáveis é no revestimento de rodovias, em que são relatadas reduções do escoamento superficial em torno de 50\% (FASSMAN e BLACKBOURN, 2010).

Por sua vez, o poço de infiltração de água pluvial, que consiste em escavar um poço no solo revestido por tubos de concreto perfurados ou tijolo assentado em crivo, sua lateral e fundo são preenchidos com brita envolta em geotêxtil. Esses sistemas operam de forma a receber as águas pluviais captadas pelas áreas de contribuição da edificação e promover a infiltração deste volume de água pluvial no solo situado dentro dos limites da área edificada. Somente durante chuvas prolongadas, em que a região de contorno do poço esteja saturada, o poço encheria e passaria a funcionar como reservatório de retenção. Caso o poço atinja sua capacidade máxima de operação, a água excedente seria conduzida por meio de um extravasor para o sistema convencional de captação de água pluvial. Podem reter e infiltrar $100 \%$ de uma determinada chuva de projeto, desde que haja disponibilidade de área e de condições adequadas de parâmetros locais, tais como: nível do lençol freático, capacidade de infiltração do solo e capacidade estrutural do solo.

Estudo desenvolvido para a avaliação do desempenho desse sistema no controle de cheias urbanas, considerando poços de $500 \mathrm{~L}$ de volume interno, aponta para reduções de 10 a 20\% na vazão de pico para chuvas com diferentes períodos de retorno. Para chuvas com período de retorno inferior a um ano, observam-se reduções de até $80 \%{ }^{18}$ Quando comparado com um poço escavado em solo sem revestimento, o poço de infiltração apresentou um coeficiente de infiltração cerca de 19 vezes maior (REIS, OLIVEIRA e SALES, 2008).

Os jardins de infiltração, por sua vez, constituem-se em uma das soluções mais simples para o controle de escoamento na fonte. São, em geral, compostos por áreas permeáveis rebaixadas e plantadas e/ou preenchidas com material granular, que recebem a descarga do volume de água de chuva precipitada sobre uma área impermeável como, por exemplo, telhados e pavimentos de uma edificação. As áreas verdes podem receber drenos transversais para facilitar a infiltração do volume de água precipitado. Esse sistema pode reduzir em até $88 \%$ o volume médio anual de escoamento superficial (JACOBSON, 2007).

As bacias de biorretenção são constituídas de uma área escavada preenchida com substrato preparado para suportar plantas e reter a água de chuva escoada para seu interior. Esta solução proporciona também o tratamento da água infiltrada na bacia, por meio do processo de fitorremediação. Assim, utiliza as funções naturais do solo e da vegetação para promover ações de cunho físico (promove o aumento da interceptação, da infiltração e da evapotranspiração e impede ou reduz os processos de assoreamento ou erosão), químico (promove a adsorção e a quelação, além da troca orgânica) e biológico (aumenta a transpiração, promove a remoção de nutrientes, e a decomposição microbiológica) (HOLZ, 2010).

Sistemas de biorretenção podem reter até 
99\% do escoamento superficial gerado em pequenas áreas urbanas, desde que o sistema seja dimensionado adequadamente para reter este volume de projeto. Entretanto, a principal característica deste sistema é o tratamento da água de chuva captada por meio da remoção de metais tais como: zinco, cobre e chumbo, de sólidos suspensos totais e nutrientes, tais como: nitrogênio e fósforo (DIETZ, 2007).

Por fim, as trincheiras de infiltração constituem-se em valas de grande comprimento e pequena largura preenchidas com material granular com porosidade acima de $35 \%$ (seixos, britas e outros), envolto em manta geotêxtil. Destina-se a reter a água precipitada por tempo suficiente no reservatório de brita formado pela trincheira, para que ocorra sua infiltração gradativamente. Desta forma, as trincheiras de infiltração funcionam como reservatórios convencionais de amortecimento de cheias. Quando o solo da região de contorno atingir sua capacidade limite de saturação, a água descarregada no sistema passa a percolar lentamente dentro do reservatório de brita até o chegar ao ponto de extravasamento. Neste momento, a água passa a contribuir com o sistema convencional de drenagem urbana.

Alguns estudos indicam que as trincheiras de infiltração, assim como os demais sistemas de infiltração, são capazes de reter e infiltrar até 100\% do volume de escoamento superficial considerado no projeto (SOUZA et al. 2002 e LIMA, 2009). Um aspecto a ser considerado é a qualidade da água a ser infiltrada, para evitar a contaminação do solo por metais pesados, derivados de petróleo, sais e outros (GÖBEL et al. 2009).

\subsection{PARÂMETROS DE PROJETO E CRITÉRIOS DE CONCEPÇÃO}

A definição prévia de parâmetros locais é necessária para o dimensionamento e para a execução dos sistemas de drenagem na fonte e busca suprir as limitações de cada solução de drenagem, propiciando maior desempenho de operação, dimensionamento econômico e funcional, além do cumprimento do propósito para o qual foi projetado, seja ele a manutenção ou o restabelecimento do balanço hídrico do local a ser ocupado. Com esse objetivo e, com base na bibliografia consultada, propõe-se que sejam definidos:

(a) Parâmetros gerais de projeto para sistemas de drenagem na fonte:

- tempo de retorno (T) e tempo de concentração (tc);

- índices pluviométricos regionais (i);

- áreas de contribuição (Ac) e coeficiente de escoamento superficial (c);

- vazão de projeto (Q);

(b) Parâmetros de projeto específicos para sistemas de drenagem na fonte baseados em soluções de infiltração de água de chuva:

- nível do lençol freático mais elevado no período sazonal;

- classificação e caracterização dos índices físicos do solo local;

- perfil do solo até a profundidade correspondente ao sistema de infiltração;

- coeficiente médio de permeabilidade (k) e taxa média de infiltração (I) do solo;

- potencial de colapsibilidade do solo (em especial solos tropicais);

- determinação e quantificação da carga poluidora e de sedimentos nas águas de escoamento superficiais;

(c) Parâmetros de projeto específicos para sistemas de drenagem na fonte baseados em soluções de filtração de água de chuva:

- definição da vegetação e do meio filtrante em função da carga poluidora a ser tratada;

- classificação e caracterização da taxa de filtração do elemento filtrante;

- determinação e quantificação da carga poluidora e de sedimentos nas águas de escoamento superficiais;

- determinação do intervalo de manutenção segundo carga de sedimentos retida no material filtrante;

- determinação do volume e da vazão de limpeza dos filtros no caso de seja realizado por fluxo reverso; 
- caso contemple infiltração deve-se considerar todos os parâmetros específicos para a concepção de sistemas de infiltração.

A partir disso, também com base na bibliografia consultada, propõem-se os seguintes critérios básicos de concepção para sistemas de drenagem na fonte:

- todo sistema de drenagem na fonte deve ser dimensionado de forma a evitar a ampliação da vazão de escoamento superficial descarregada para fora da área ocupada;

- em sistemas que acumulem água no seu interior, a infiltração ou o aproveitamento da água de chuva deve ser rápida, permitindo o esvaziamento do volume necessário ao amortecimento de vazão do hidrograma de projeto. Para tanto, recomenda-se que o tempo de esgotamento seja entre 6 a 12 horas, permitindo assim, que o sistema funcione adequadamente durante a ocorrência de chuvas consecutivas;

- o tempo de descarga de sistemas de drenagem na fonte, entre 6 e 12 horas, também evita que insetos se proliferem no seu interior;

- sistemas que promovam a infiltração de água no solo não deve comprometer a estabilidade do terreno ou de qualquer outra estrutura periférica. Desta forma, recomenda-se que os sistemas de infiltração de águas pluviais sejam construídos com profundidades inferiores ao nível da base das fundações e, afastados das mesmas;

- não deve-se promover a infiltração de água em solos de terrenos que tenham características colapsíveis como, por exemplo, alguns solos tropicais não saturados que tendem a retrair quando submetidos a variação de umidade;

- estruturas de infiltração de grande profundidade devem ser evitadas, pois geram grandes gradientes hidráulicos o que pode acarretar a erosões internas e promover recalques;

- a infiltração da água de chuva no solo não deve ocasionar contaminação do solo e do lençol freático, para tanto, recomenda-se não construir sistemas de infiltração a menos de $1,50 \mathrm{~m}$ de afastamento do nível mais elevado do lençol freático em um período sazonal;

- é desejável que toda a água de chuva captada dentro do lote edificado deva ser conduzida inicialmente para o as unidades de drenagem na fonte e, somente ser descarregada no sistema urbano de água pluvial após atingir sua capacidade máxima de operação;

- os sistemas de drenagem na fonte devem ser duráveis à colmatação e ao assoreamento, de forma a manter a capacidade máxima do sistema de drenagem pelo maior intervalo de tempo possível sem manutenção.

- recomenda-se que os sistemas de drenagem na fonte sejam acessíveis de modo a facilitar eventuais práticas de manutenção destas unidades;

- os sistemas de drenagem na fonte não devem ocasionar desconforto à vizinhança, ou seja, não deve possibilitar alagamentos, ruídos ou vibrações devido a altura de descarga de água, mau cheiro ocasionado pelo acúmulo de matéria orgânica em decomposição, risco à estabilidade das edificações, entre outros.

Alguns estudos indicam que a execução de sistemas baseados nas práticas de LID podem resultar em estruturas entre $15 \%$ a $80 \%$ mais baratas do que sistemas baseados em técnicas convencionais, ou seja, unidades de captação do tipo boca de lobo associadas a poços de visita e galerias pluviais para o transporte da água de chuva captada. Apesar disto, também foram identificados casos em que as soluções baseadas em práticas LID resultam em maior ônus, o que ressalta a necessidade de realização de estudos prévios de avaliação econômica para cada caso em particular. Os custos de manutenção tendem a ser similares em ambas as tipologias de sistema de drenagem (Environmental Protection Agency - EPA, 2009).

\subsection{BENEFíCIOS E LIMITAÇÕES TÉCNICAS DA ADOÇÃO DE PRÁTICAS LID}

As práticas de desenvolvimento de baixo impacto têm grande potencial quanto à mitigação dos impactos ocasionados pelo processo de desenvolvimento urbano (TRINKAUS e CLAR, 2010):

(a) Benefícios ambientais 
- melhoria da qualidade da água urbana devido à redução do transporte de sedimentos, de nutrientes e de outras cargas poluidoras para o leito dos mananciais receptores do escoamento pluvial;

- redução do escoamento superficial devido ao aumento no tempo de concentração (tc) e redução do volume escoado;

- manutenção do balanço hídrico e preservação da integridade biológica e ecológica do sistema natural;

- promoção de pontos de recarga de mananciais subterrâneos;

\section{(b) Benefícios públicos}

- redução dos custos com infraestrutura urbana e manutenção;

- equilíbrio entre necessidade de desenvolvimento e preocupação com a proteção ambiental

- aumento do número de parceiros públicos e privados na colaboração da proteção ambiental;

- manutenção do balanço hídrico e preservação da integridade biológica e ecológica do sistema natural;

\section{(c) Benefícios na infraestrutura de}

\section{desenvolvimento urbano}

- redução dos custos com a ocupação de áreas e movimentação do solo (área a ser urbanizada) e com infraestrutura;

- melhoria da qualidade de vida urbana;

- aumento do número de áreas urbanas e lotes comercializáveis, devido a menor área necessária para a implantação dos sistemas de drenagem convencionais e, benefício do uso da estratégia de marketing verde;

Apesar dos benefícios proporcionados pela aplicação das práticas de desenvolvimento de baixo impacto é necessário ressaltar que este modelo de concepção de sistemas de drenagem é relativamente novo e, ainda necessita de investigações mais aprofundadas e monitoramento em longo prazo para que a técnica e a metodologia sejam totalmente consolidadas. Dentre as limitações dos sistemas de drenagem na fonte embasados em práticas LID, destacam-se:
- sistemas que promovem a infiltração da água captada nem sempre são viáveis devido à baixa capacidade de permeabilidade do solo ou elevado nível do lençol freático;

- a capacidade estrutural do solo é um fator limitante as soluções de drenagem que promovem infiltração devido à grande variação na taxa de umidade;

- os sistemas de infiltração não são adequados à áreas sujeitas ao efeito das marés (SOUZA et al. 2002);

- existe grande risco de contaminação da água e do solo pelo carreamento de poluentes para o interior de sistemas de infiltração;

- valores elevados de sólidos encaminhados para dentro dos sistemas de drenagem na fonte podem ocasionar a redução precoce do desempenho desses sistemas em função de processos de colmatação e assoreamento;

- a fertilização excessiva de sistemas como biorretenção e coberturas verdes podem elevar a quantidade de fósforo na água que percola pelo sistema;

- uso de modelos hidrológicos convencionais tem se mostrado inadequado para o dimensionamento de sistemas baseados nas técnicas de LID, devido ao grande número de variáveis relacionadas às condições do solo, eventos de chuvas, parâmetros de infiltração, evapotranspiração (BEYERLEIN, 2009);

- declividades elevadas nas superfícies que promovem a captação de água pluvial podem ocasionar mau funcionamento dos sistemas de drenagem na fonte;

- a falta de conhecimento técnico a respeito de funcionamento destes sistemas pode ocasionar a longo prazo situações não previstas, as quais podem necessitar ações de intervenção ainda não conhecidas;

- desconhece-se a real eficiência das praticas LID quando implementadas em larga escala no ambiente urbano.

3.3 DESAFIOS METODOLÓGICOS PARA A APLICAÇÃO DE EM LARGA ESCALA E NECESSIDADES DE PESQUISAS IDENTIFICADAS 
A aplicação das práticas de desenvolvimento de baixo impacto ambiental estabelece a abordagem de um conceito ainda pouco usual na concepção de sistemas de drenagem urbana. Apesar do aumento do número de pesquisas e publicações geradas sobre o tema na atualidade, a relativa baixa aplicação destas ferramentas encontra-se associada aos seguintes fatores:

- falta de elaboração de normalização especifica para a concepção destes sistemas;

- necessidade de capacitação dos profissionais responsáveis pelo projeto, execução e manutenção, baseada em técnicas convencionais de concepção de sistemas de drenagem urbana;

- falta de desenvolvimento de metodologias adequadas de dimensionamento que correlacione não somente ensaios de laboratório, mas também, ensaios in loco, no caso de sistemas de drenagem que sejam dependentes de parâmetros geotécnicos e hidrológicos;

- existência de um pré-conceito a respeito da viabilidade econômica de aplicação destas ferramentas;

- necessidade de esclarecimento quanto aos fatores limitantes para a aplicação dos sistemas de drenagem na fonte, tais como: capacidade estrutural do solo, capacidade de infiltração e permeabilidade, área disponível, grau de saturação do solo, nível do lençol freático, acessibilidade e manutenibilidade;

- escassez de componentes e materiais específicos para a execução de sistemas de drenagem na fonte no país ;

- existência de um grande número de variáveis e particularidades nas formas de concepção de sistemas de drenagem na fonte associadas a parâmetros locais.

Analisando-se a atual situação de desenvolvimento das ferramentas associadas às práticas LID, pode-se afirmar que o emprego desta tecnologia em países como Austrália, Alemanha e Estados Unidos já apresenta um elevado grau de maturidade e consolidação de tecnologias aplicáveis às particularidades destas regiões. Por outro lado, a aplicação em larga escala em países emergentes ainda depende da superação de vários desafios:

- estabelecimento de meios que possibilitem a agregação de valor aos sistemas de drenagem na fonte por meio do estabelecimento de diretrizes e de políticas publicas de incentivo a adoção de sistemas compensatórios de drenagem na fonte;

- definição metodologias claras de projeto, tais como: requisitos de desempenho, critérios de dimensionamento, fatores limitantes e outros;

- desenvolvimento de modelos abertos que auxilie na tomada de decisão quanto à viabilidade e concepção de sistemas de drenagem na fonte;

- capacitação técnica adequada aos profissionais envolvidos com o projeto, execução, operação e manutenção dos sistemas de drenagem na fonte;

- amadurecimento da indústria nacional para o desenvolvimento e distribuição de sistemas e componentes de menor custo nas fases de execução, operação e manutenção;

- consolidação de estudos que confirmem a viabilidade econômica e eficiência técnica da adoção de tais sistemas;

- definição dos riscos associados à implementação dos sistemas de drenagem na fonte;

- sensibilização dos usuários quanto a adoção de técnicas de drenagem que subsidiem o desenvolvimento de baixo impacto.

\section{CONCLUSÕES}

Os sistemas de drenagem na fonte consistem em soluções técnicas de controle de escoamento superficial baseadas no conceito de desenvolvimento de baixo impacto. Supõe-se que a tendência de adoção de sistemas de infiltração de água de chuva para o controle da vazão de escoamento superficial em lotes urbanos é baseada no sentimento de que esta é a solução de maior sustentabilidade dentre as técnicas de drenagem na fonte. Apesar disto, a falta de conhecimento mais aprofundado por parte do meio técnico e, também, de consolidação de diretrizes e critérios de concepção mais aprimorados, em muitos casos 
convergem para o uso inadequado desta solução. Apesar de limitado a uma revisão bibliográfica, este estudo reuniu informações de pesquisas relevantes já publicadas sobre o tema com intuito de responder questões levantadas sobre o propósito, as formas de aplicação, os principais parâmetros de concepção, o desempenho, a viabilidade econômica e as limitações desta ferramenta de controle de escoamento superficial na fonte onde ele é gerado.

Dentre as pesquisas avaliadas, os sistemas de drenagem baseados na infiltração de água de chuva demonstraram ser adequados para a execução de soluções que visem impedir a ampliação da vazão de descarga de água pluvial para fora do lote ou área ocupada (micro bacia). 0 desempenho dos sistemas depende da sua forma de concepção e, também, de limitações proporcionadas por parâmetros como: baixa permeabilidade do solo, elevado nível do lençol freático, baixa estabilidade do solo, potencial de colapsibilidade, elevada carga poluidora e de sedimentos, declividade da superfície, temperatura ambiente entre outros.

Apesar de muitos questionamentos que colocam em dúvida a viabilidade econômica de implementação de práticas LID, estudos recentes publicados pela EPA (2009), demonstram que tais sistemas podem ser bem mais econômicos que a implantação de sistemas de drenagem baseadas apenas em conceitos convencionais.

Por fim, assim como exposto nas pesquisas realizadas por Dietz (2007) e Reis et al. (2008) a identificação de fatores limitantes que impedem que as práticas de desenvolvimento de baixo impacto sejam abortadas com maior abrangência durante a concepção de sistemas de drenagem urbanos, evidencia a necessidade de transposição de desafios que envolvem a criação de políticas públicas de incentivo, a determinação e consolidação de metodologias e critérios mais precisos de concepção e dimensionamento, a capacitação do meio técnico, o amadurecimento da indústria em âmbito mundial, a definição dos riscos envolvidos entre outros.

Deste modo, pesquisas com enfoque na correlação de parâmetros geotécnicos e hidrológicos poderiam ser associadas à identificação de metodologias mais precisas para o desenvolvimento de modelos que facilitem a tomada de decisão e escolha dos sistemas de drenagem na fonte aplicados a uma determinada região. Discussões sobre propostas de políticas públicas de incentivo a ampliação de técnicas de drenagem na fonte, além de estudos mais aprofundados sobre viabilidade econômica, ambiental e social, poderiam contribuir com sugestões para a agregação de valor a esta tecnologia, o que implicaria em uma maior adoção desta ferramenta por parte do meio técnico.

Assim, estudos voltados para a resolução das limitações levantadas neste trabalho contribuiriam para uma melhor disseminação do conhecimento a respeito da aplicação mais rigorosa das ferramentas de drenagem na fonte.

\section{REFERENCIAS BIBLIOGRÁFICAS}

ACIOLI L. A., AGRA S. G., GOLDENFUM J. A., SILVEIRA A. L. L. Experimental study of permeable reservoir pavements for surface runoff control at source in a subtropical region. Proceedings of the Novatech 2004. Sustainable techniques ans strategies in urban water management. Villeurbanne - France : Groupe de Recherche Rhône-Alpes sur les Infrastructures et I'Eau, 2004. v. 1. p. 771-778.

ANA - Agência Nacional de Água. Ministério do Meio Ambiente. Disponibilidade e demandas de recursos hídricos no Brasil. Cadernos de recursos hídricos 2. Maio, 2007.

ARAÚJO P.R., TUCCI C.E.M., GOLDENFUM, J. A. Avaliação da Eficiência dos Pavimentos Permeáveis na Redução de Escoamento Superficial. RBRH - Revista Brasileira de Recursos Hídricos. ABRH, vol. 5, no 3, jul-set/2000. 2129p.

BERTONI J.C., TUCCI C.E.M. Urbanización. Tucci, CEM, Bertoni, JC (Org.) In: Inundações Urbanas na América do Sul. Porto Alegre: ABRH. Cap. 1, 1ed. 2003. p.1-9.

BEYERLEIN D., Why Single-Event Modeling Doesn't Work For LIDs. Proceedings of the Stormcon 2009, Anaheim, C.A. CCS - Clear Creek Solutions, Inc. 2009. 
CARVALHO E.T. L. Avaliação de Elementos de Infiltração de Águas Pluviais na Zona Norte da Cidade de Goiânia. Dissertação (Mestrado) - Universidade Federal de Goiás. Goiânia. Goiás, 2008. 233p.

DIETZ, M.E. Low Impact Development Practices: A Review of Current Research and Recommendations for Future Directions. Water Air Soil Pollut. Springer Science. 2007. 351-363p.

DONOFRIO J, KUHN Y, MCWALTER K, WINSOR M. WaterSensitive Urban Design: An Emerging Model in Sustainable Design and Comprehensive Water-Cycle Management. National Association of Environmental Professionals. San Diego - CA. 2009. 11p.

Environmental Protection Agency. Managing Stormwater With Low Impact Development Practices: Adressing Barriers to LID. USEPA. 2009. 7p.

FASSMAN E., BLACKBOURN S. Permeable Pavement Performance Over 3 Years of Monitoring. Proceedings of the 2010 International Low Impact Development Conference, San Francisco, Califórnia, 2010.

GÖBEL P., ZIMMERMANN J., KLINGER C., STUBBE H., COLDEWEY W.G. Recommended urban storm water infiltration devices for different types of run-off under varying hydrogeological conditions. Journal of Soils and Sediments, Urban Impact on soils and groundwater. 2009 , v. 8 , n. 4, 231-238.

JACOBSON D. Burnsville Rainwater Garden Retrofit Project. Proceedings of the $18^{\text {th }}$ Nonpoint Source Pollution Conference. City of Burnsville. 2007.

LIMA V. C. G. R. Análise experimental e numérica de trincheiras de infiltração em meio não saturado. Dissertação de mestrado. São Paulo: Escola de Engenharia de São Carlos. Universidade de São Paulo, 2009.

HINMAN, C. Low Impact Development: Technical Guidance Manual For Puget Sound. Washington State University Pierce County Extension. Puget Sound Action Team. Tacoma -WA, 256p. 2005.

HOLZ T. Stormwater Strategies Community Responses to Runoff Pollution: Low Impact Development. SCA Consulting Group, 2001. Lacey, Washington. Disponível em:

http://www.nrdc.org/water/pollution/storm/chap12.asp > Acessado em 20 de julho de 2010.

IBGE - Instituto Brasileiro de Geografia e Estatística. Censos 2006. 2006.
METROPOLITAN COUNCIL ENVIRONMENTAL SERVICES. Minnesota Urban Small Sites BMP Manual: Stormwater Best Management Practices for Cold Climates. Barr Engineering Company. St. Paul, MN. 2001.

NASCIMENTO N.O., BAPTISTA M. B. Técnicas Compensatórias em Águas Pluviais. In: Righetto, Marozzi (Coord.) In: Manejo de Águas Pluviais Urbanas. Rio Grande do Norte. ABES - PROSAB , Cap. 4, 2009. $397 p$.

REIS, R.P.A., OLIVEIRA L.H., GONÇALVES O.M., ILHA M.S.O. Indicators of water supply and drainage systems im Brazilian low income dwellings considering environmental sustainability. Proceedings of the: 32 은 International Symposium CIB W062 - Water Supply Drainage for Buildings. CIB W062 - Water Supply Drainage for Buildings. Taipei, Taiwan. 2006. v.1. p.1 12.

REIS R. P. A., OLIVEIRA L. H., SALES M. M. Sistemas de drenagem na fonte por poços de infiltração de águas pluviais (On-lot drainage systems with rain water infiltration wells). Revista Ambiente Construído Associação Nacional de Tecnologia do Ambiente Construído, 2008, v. 8, n. 2, p. 99-117.

SCHILLING W. Cisterns Against Storms. In: Featherstone $\mathrm{RE}$, James A. Urban Systems Drainage. London: Computational Mechanics Centre. 1982. p. 7.49-4.60.

SILVA B.L., MOREIRA T., KOIDE S., CAMPANA N.A. Avaliação da infiltração em revestimentos com superfícies permeáveis. Fundatión para el Fomento de La Ingeniería del Agua. Revista Ingeniería del Agua, v. 16, n.3, p. 1-10, 2009.

SOUZA V.C.B., GOLDENFUM J.A., BARRAUD S. An experimental and numerical study of nfiltration trenches in urban runoff control. Proceedings of the $9^{\text {th }}$ International Conference on Urban Drainage - ICUD. Portland. International Conference on Urban Drainage ASCE - American Society of Civil Engineers 2002.

TRINKAUS S., CLAR M. A low Impact Development (LID) Model Ordinance and Guidance Document. Proceedings of the World Environmental and Water Resources Congress 2010: Challeges of Change. ASCE. 2010. $6 p$.

URBONAS B, STAHRE P. Stormwater Best Management Practices and Detention. Prentice Hall, Englewood Cliffs, New Jersey, 1993. 450p.

WORLD ECONOMIC FORUM. Water Initiative Future Water Needs. Genova, Switzerland. 2009. 68p. 
WORLD RESOURCES INSTITUTE. Populational, Helth and Human Well-Being - Urban and Rural areas: Urban

Population. EarthTrends Searchable Database. Washington - DC. 2007. Disponível em: <http://earthtrends.wri.org/searchable_db/index.php?th eme $=4>$ Economic and Social Council. Acesso em 15 de fevereiro de 2009. 